\title{
Exploring Factors Related to First Year College Students' Academic Achievement in Indonesia
}

\author{
$1^{\text {st }}$ Airin Triwahyuni \\ Faculty of Psychology \\ Universitas Padjadjaran \\ Bandung, Indonesia \\ airin.triwahyuni@unpad.ac.id \\ $4^{\text {th }}$ Hery Susanto \\ Faculty of Psychology \\ Universitas Padjadjaran \\ Bandung, Indonesia
}

\author{
$2^{\text {nd }}$ Tiara R. Widiastuti \\ Faculty of Psychology \\ Universitas Padjadjaran \\ Bandung, Indonesia
}

\author{
$3^{\text {rd }}$ Whisnu Yudiana \\ Faculty of Psychology \\ Universitas Padjadjaran \\ Bandung, Indonesia
}

\begin{abstract}
Grade Point Average (GPA) was commonly used as a measure of college students' academic achievement. There was no analysis yet regarding factors related to academic achievement for college students in Indonesia. The purpose of this study is to predict factors related to first year academic achievement. The knowledge about those factors could be used by freshmen and study program coordinator to assist students in facing academic challenges. Participants were 156 first-year students in a faculty of State University $X$. A structural equation model (SEM) using IBM SPSS AMOS version 21 was used to analyze the data. The result shows that first semester grade point was directly predicted by Intelligence weighted likelihood estimates (WLE) score, and Learning resources, Study program priority choice, First adaptation problem, and Mother education. While Gender indirectly predicted first year academic achievement through learning resources. Rule inference ability was the strongest predictor from intelligence score, while perceptual speed ability was the weakest. The frequency of using Slideshows as a learning resource evidently affect first year student academic achievement. Further investigation with more students' factors and adding lecturer level factors are recommended.
\end{abstract}

Keywords-College Student, Academeic, Achievement, Indonesia

\section{INTRODUCTION}

College students' achievement usually measured using Grade Point Average (GPA). Despite students' success would not sufficient to be predicted solely from GPA, many students, parents, and employer consider GPA as an indicator of students' accomplishment. First semester is a crucial time for the students because adaptation could be an issue for freshmen. First year college students encounter many changes. Indonesian secondary school still emphasize on teacher centered learning. In the other hand, college expects students to be more active in individual learning. These changes could be a source of stress for freshmen. Therefore, academic achievement as one of adjustment outcomes could be affected by this change. Different expected learning behavior in secondary school and college also could be a source of adaptation problem (Hurtado, S., Han, J. C., Sáenz, V. B., Espinosa, L. L., Cabrera, N. L., \& Cerna, O. S., 2007)

Many research, found consistent result that intellectual ability has positive correlation with academic achievement (Deary, I. J., Strand, S., Smith, P., \& Fernandes, C., 2007; Busato, V. V., Prins, F. J., Elshout, J. J., \& Hamaker, C., 2000). Similar with intellectual ability, many research found motivation has significant correlation with academic achievement. In the beginning of the study concerning factors related to achievement, motivation usually define as drive. However, educational setting made it specific as achievement motivation (Busato, V. V., Prins, F. J., Elshout, J. J., \& Hamaker, C., 2000). Interest is said to be the purpose of drive (Ryan, R. M., \& Deci, E. L., 2000); providing reasons for actions and dispositions (Roth, W. M., \& Hsu, P. L., 2008). Recent studies shows that interest had a strong effect, within and between person, to academic achievement (Jansen, M., Lüdtke, O., \& Schroeders, U., 2016).

Demographics factors, such as age and gender were repeatedly mentioned on different studies. Age is said had effect on achievement which younger students tend to get better grades (Harris, D., 1931). However, recent findings show different result. One study related to demographics data showed no significant correlation between age and academic achievement but significant correlation with gender on health science students (Aisha, W. A. D. A., Wagner, D. M., Al Qassab, F., Mohamed, M., Hamad, M., \& Al Sharbatti, S., 2016). In other study on secondary school students, no relation was found between age and grades (Fritz, R. A., 1933; Reed, S. L., 2014). Gender, has enormous evidence that shows correlation between female and achievement. Female students tend to get better grades than male students (Voyer, D., \& Voyer, S. D., 2014; Fortin, N. M., Oreopoulos, P., \& Phipps, S. 2015; 
Aisha, W. A. D. A., Wagner, D. M., Al Qassab, F., Mohamed, M., Hamad, M., \& Al Sharbatti, S., 2016). The other study found gender has indirect effect to academic achievement (Torenbeek, M., Jansen, E., \& Hofman, A., 2010). Developmental studies, mostly on children, shows positive correlations between mothers' educational attainment and children's test scores, academic outcomes, and cognitive development (Davis-Kean, 2005; Haveman \& Wolfe, 1995; Harris, 1931).

The purpose of this study is to predict factors related to first year academic achievement. The knowledge about those factors could be used by freshmen and study program coordinator to assist students in facing academic changes. According to clinical literature (DSM V), six month is a time range for normal adaptation process. Intelligence factors (Deary, I. J., Strand, S., Smith, P., \& Fernandes, C., 2007), motivation (Busato, V. V., Prins, F. J., Elshout, J. J., \& Hamaker, C., 2000), demographics factors (Hackett, G., Betz, N. E., Casas, J. M., \& RochaSingh, I. A, 1992; Torenbeek, M., Jansen, E., \& Hofman, 2010), adaptation problems (Harackiewicz, J. M., Barron, K. E., \& Elliot, A. J, 1998), learning source and learning strategies were predicted to have correlation with academic achievement on first semester students.

\section{MATERIALS AND METHODS}

This study is a cross-sectional study to find out the influence of intelligence, demographics factors (i.e. age, gender, and parents' education), interest, adaptation problem, and learning strategies and resource on first year academic achievement. Participants were first-year psychology students at the University $X$. The data collection was conducted at the end of the first semester. Before the data collection, all students were asked to sign a consent form which explained purpose of the study, confidentiality, voluntary participation and presented a contact number if the parents want to ask questions to the researcher. Only were students who agreed to participate in the study included in the study. Descriptive statistics were calculated using IBM SPPS Version 21. A structural equation modeling data analysis using IBM AMOS version 21 to describe the relationship of factors related to academic achievement.

The variables in this study were:

- Academic Achievement: First semester grade point average was used to represent first year students' academic achievement (GP1).

- Intelligence: Intelligence score were collected using Tes Inteligensi Kolektip Indonesia-Tinggi (TIKI-T). TIKI-T is used for students in senior high school or first year of college to make decisions about tertiary education path (Drenth, P.J.D., Dengah, B., et al, 1976). The test battery consists of 11 subtests i.e. Arithmetic (AR), Components (CO), Word Relation
(WR), Figure Classification (FC), Number Series (NS), Accuracy and Speed (AS), Visualization (VI), Spatial Orientation (SO), Verbal Analogies (VA), Hidden Figures (HF), and Word Composition (WC). The confirmatory factor analysis of IQ using TIKI subtests model was showed a good fit ( $\mathrm{p}$-value $=0.07$, CMIN/Df $=1.59$, RMSEA $=0.06, \mathrm{CFI}=0.93)$. The intelligence scores for each subtest were converted into Rasch logit scale i.e. weighted likelihood estimate (WLE) using Conquest 4.

- Interest: To measure interest, one question is used. The question is about study program priority on admission selection (PRI).

- Demographics Data: Gender (GEN), age (AGE), and parents' education (MED and FED) were chosen to be used as predictor of academic achievement based on literature review and the availability of the data.

- Adaptation Problem: Adaptation problem was measured using one yes or no question, i.e. Did they have difficulties when they first attend college? (FPR)

- Learning Strategies and Resource: Learning resources were consisted of textbook (TXT), lecturer slideshow (SHW), journal articles (JOU), web (WEB), and students' notes (CNT). Participants were asked to rate their usage frequencies (1-5) on each learning resource. The confirmatory factor analysis for learning resources using initial model of 5 questions were showed a moderately fit indices even though all question had significant loading on learning resources. Therefore, 1 question concerning Journal which had the lowest estimation was deleted. The final model of 4 question now showed a good fit ( $\mathrm{p}$-value $=0.83$, $\mathrm{CMIN} / \mathrm{Df}=0.18, \mathrm{RMSEA}=0.00, \mathrm{CFI}=1.00)$. While, learning strategies were removed from the research model because the confirmatory factor analysis for learning strategy was showed poor fit indices with all question had no significant loading on learning strategy.

\section{RESULT}

The final sample consisted of 156 from 165 first year psychology students take part in this study. Descriptive statistics showed approximately $83 \%$ of the participant was female and the rest was male. The age of the participants were ranged from 17 to 21 years old. The majority was 19 years old $(60.3 \%)$. Most parents had bachelor degrees, the fathers were $56.4 \%$ and the mothers were $45.5 \%$. In Indonesia, when students apply to university, they can choose up to three study programs. Most of the participants chose psychology as the first study program on admission selection (75.6\%). Lastly, $78.2 \%$ students reported that they had adaptation problem when they became freshmen.

TABLE I. GOODNESS OF FIT INDEX FOR FACTORS RELATED TO FIRST YEAR COLLEGE STUDENTS' ACHIEVEMENT
\begin{tabular}{|l|c|c|c|c|c|c|c|c|}
\hline Model & CMIN & $\mathrm{df}$ & $\mathrm{Sig}$ & CMIN/df & IFI & TLI & CFI & RMSEA \\
\hline Cut-off & -- & -- & $>.05$ & $<2 ;<5$ & $>.90 ;>.95$ & $>.90 ;>.95$ & $>.90 ;>.95$ & $<.08<.06$ \\
\hline Initial & 391.56 & 207 & .00 & 1.89 & .73 & .65 & .71 & .08 \\
\hline
\end{tabular}




\begin{tabular}{|l|c|c|c|c|c|c|c|c|}
\hline Model & CMIN & df & Sig & CMIN/df & IFI & TLI & CFI & RMSEA \\
\hline Final & 252.27 & 169 & .00 & 1.49 & .86 & .81 & .85 & .06 \\
\hline
\end{tabular}

Note: CMIN = Chi-square $; \mathrm{df}=$ Degree of freedom; TLI = Tucker-Lewis Index; CFI = Goodness - of-Fit Index; RMSEA = Root Mean Square Error of Approximation

An initial model was developed based on literature review. As a preliminary step, a confirmatory factor analysis (CFA) was done to test the hypothesis derived from literature reviews. Table 1 shows comparison between initial and final model of factors related to first year college students' achievement. After non-significant variables were removed from the model, final model showed better fit indices. This means the final model is more suitable to predict grade point average on first year university student.

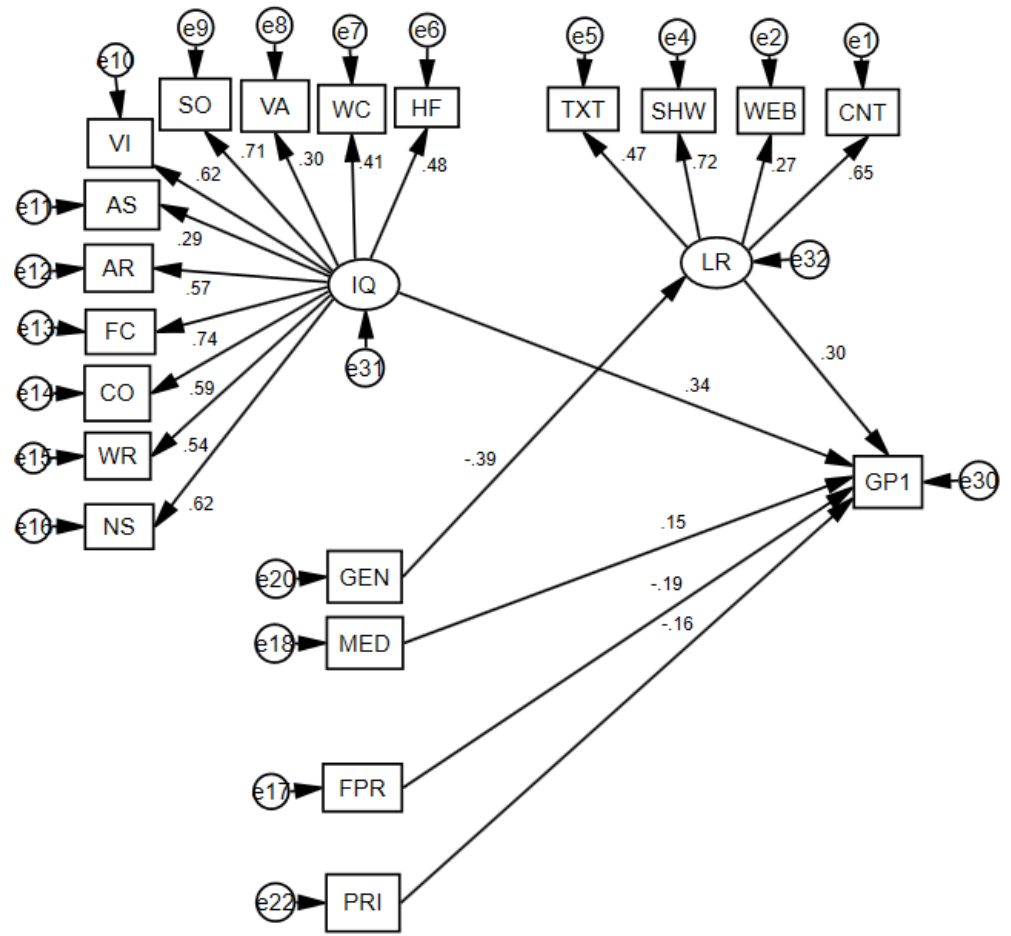

Fig. 1. Final Model of Factors Related To First Year College Students' Achievement

Figure 1 shows structural equation model (SEM) of the final model of factors related to first year students' achievement. Average grade point $1^{\text {st }}$ semester (GP1) was predicted directly by Intelligence score (IQ), Learning resource (LS), Interest (PRI), Adaptation problem (FPR) and demographic variables, i.e. Mother Education (MED), gender (GEN) directly and indirectly through learning resource. The final model explained $29 \%$ differences on First semester Average Grade Point.

\section{DISCUSSION}

This result showed Intellectual ability was found as a predictor of academic achievement and fluid intelligence i.e. Induction as the specific narrow ability to predict first year academic achievement. Gender has indirect effect on students' academic achievement through learning resources; partly confirmed literature reviews which found direct effect from gender to academic achievement (Harris, D., 1940). Learning resources, i.e. Slideshows and Class notes had effect on students' first year academic achievement.

The probable reason interest had only in a small magnitude effect on academic achievement was because study program admission priority measured not only interest. In Indonesia, about $70 \%$ students followed university preparation class (Intan, 2016). Most of those student motivation was entered the university (Eriany, P., Hernawati, L., \& Goeritno, H., 2014) thus university preparation class thought secondary graduate students to choose university majoring based on their preparation class result not emphisize on their interest. Another explanation is study program admission only measure initial interest or initial commitment not interest as a learning drive (Torenbeek, M., Jansen, E., \& Hofman, A., 2010).

The result of this research is consistent with previous research about student background characteristics. The higher the intelligence score, the more often students use learning resource, and the higher the students' mother education, so do the average grade point of first year students. Furthermore, students with no adaptation problem and the more interest on their study program choice, thus the higher their first semester average grade point.

Intelligence has been proven as a strong predictor of academic achievement (Deary, I. J., Strand, S., Smith, P., 
\& Fernandes, C., 2007; Busato, V. V., Prins, F. J., Elshout, J. J., \& Hamaker, C., 2000; Andersson \& Keith, 1997; Harris, D., 1940). It explains approximately $20 \%$ varians of academic achievement (Neisser et al., 1996). In this research, all subtest in intelligence score had significant effect on academic achievement of first year students. Figure classification was the highest (.74), followed with Spatial Orientation (.71). The figure classification task is finding the rule that govern a set of shapes, thus it supposed to measure rule inference or induction ability. According to Cattel-Horn-Caroll (CHC) intelligence theory, induction is categorized as fluid intelligence (Gf), includes the ability to reason, form concepts, and solve problems using unfamiliar information or novel procedures (McGill \& Dombrowski, 2019). While spatial orientation task was finding two same shapes among other shapes which had different reflected position. The ability measured by spatial orientation was spatial ability or visual-spatial processing (Gv). Spatial ability had high correlation with educational performance particularly in science, technology, engineering and mathematics (Buckley, Seery, \& Canty, 2018). In addition Gv, spatial orientation subtest also measured perspective taking as its unique factor (Buckley et al., 2018).

Accuracy and speed subtest had the lowest contribution on predicting academic achievement of first year students (.29), followed with Verbal analogy subtest (.30). Based on Accuracy and speed subtest task which is finding differences and similarities on simple object accurately and fast, it similar to perceptual speed-compare narrow ability on the perceptual speed (Gs) broad ability. Actually, verbal analogy task was also rule inference, almost the same with figure classification subtest. The difference was in the type of the items, verbal analogy was using words while figure classification was using shapes. This result differ with previous finding stated analogical reasoning as a key component of intelligence (Sternberg, 1977), learning, understanding our environment, and generating novel ideas (Dunbar \& Blanchette, 2001). In the other hand, verbal subtest usually measure crystallized intelligence (Gc). It includes the breadth and depth of a person's acquired knowledge, the ability to communicate one's knowledge, and the ability to reason using previously learned experiences or procedures.

The ability to face solve novel problem was important because college freshmen face new academic situations. This ability enables them to find the "rule" in the new environment of college, therefore their chances to adapt in the new environment is higher, especially to adapt with college academic demand (Downey, Lomas, Billings, Hansen, \& Stough, 2014). On the other hand, how fast and accurate freshmen students to find differences and similarities on simple subject had less effect on first year students' academic achievement. Academic demands and college life was not a simple matter that can be solve merely using the ability to find similarities and differences.

Learning resources had been found as an important factors affecting students' academic performance (Yara \&
Otieno, 2010). However learning resources usually seen as school factor, not individual factor. The finding showed that the frequency of using certain learning resources had effect on students' academic achievement. The frequency of slideshow had stronger effect among three other learning resource (web, textbook, and class note). Lecturers used slideshow in the class and usually distributed the material to the students. In general, students who frequently used lecturer slideshow as their first semester learning resources had higher first semester academic achievement. Class note was also frequently used as first semester students' learning resources. The effect was quite strong, even though not as strong as the slideshows.

New finding in this study was adaptation problem, students' difficulties when they first attend college, and interest which measured by students priority when they choose study program had effect on their first year academic achievement. The other was the calculation of intelligence score using logit score should gave more accurate calculation on student intelligence score, because the differences between each correct answer was equal (Boone, 2016). Analysis using raw score may not linear and equal interval therefore mathematical operation inappropriate (Boone, Yale, \& Staver, 2014).

For more scientific and practical purpose it is important to expand this study into a longitudinal study. Students who has participate in this study should be followed until they graduated (Busato, V. V., Prins, F. J., Elshout, J. J., \& Hamaker, C., 2000; Harris, D., 1940). The result also need to compared with another group of students in different admission year. A better measure of interest, and prior achievement records (Busato, V. V., Prins, F. J., Elshout, J. J., \& Hamaker, C., 2000) is reccomended and another source of data such as lecturer level factors could give a better understanding about students' learning proccess and achievement.

\section{CONCLUSION}

This study purpose is to predict factors related to first year academic achievement for freshmen students. An initial model derived directly from literature review was not fit to explained factors related to first year academic achievement for psychology students of university $\mathrm{X}$. Nonetheless, after examinations on p-value significancy, a quite fit model could be generated from the data. Almost all hypothesized factors, intellegence WLE score, learning resource, interest, adaptation problem, and demographics data, except learning strategy could be used to predict students' achievement. Though not all sub-factors has significant effect on students' achievement. Knowledge about factors related to first year academic achievement gives broader understanding about how intelligence WLE score, demographic data, learning resources, interest, and adaptation problem affected grade point in first semester.

\section{REFERENCES}

[1] Aisha W A D A, Wagner D M, Al Qassab F, Mohamed M, Hamad M and Al Sharbatti S 2016 Iranian journal of public health 45(5) p 699 
[2] American Psychiatric Association 2013 Diagnostic and statistical manual of mental disorders (DSM-5®). (Washington DC: American Psychiatric Pub)

[3] Boone W J 2016 CBE Life Sciences Education 15(4)

[4] Boone W J, Yale M S and Staver J R 2014 Rasch Analysis in the Human Sciences (Springer Science+Business Media Dordrecht)

[5] Buckley J, Seery N and Canty D 2018 Educational Psychology Review 30(3) p 947

[6] Busato V V, Prins F J, Elshout J J and Hamaker C 2000 Personality and Individual differences 29(6) p 1057

[7] Buckley J, Seery N and Canty D 2018 Educational Psychology Review 30(3) p 947

[8] Davis-Kean P 2005 Journal of Family Psychology 19 p 294

[9] Deary I J, Strand S, Smith P and Fernandes C 2007 Intelligence 35(1) p 13

Downey L A, Lomas J, Billings C, Hansen K and Stough C 2014 Canadian Journal of School Psychology 29(1) p 40

[10] Drenth P J D, Dengah B, Bleichrodt N, Soemarto and Poespadibrata S 1977 Test lntelligensi Kolektip Indonesia (Lisse: Swets \& Zeitlinger)

[11] Dunbar K and Blanchette 2001 Trends in cognitive sciences 5(8) p 334

[12] Eriany P, Hernawati L and Goeritno H 2014 Psikodimensia 13(1) p 115.

[13] Fortin N M, Oreopoulos P and Phipps S 2015 Journal of Human Resources 50(3) p 549

[14] Fritz R A 1933 Journal of applied psychology 17(4) p 439

[15] Hackett G, Betz N E, Casas J M and Rocha-Singh I A 1992 Journal of Counseling Psychology 39(4) p 527

[16] Harackiewicz J M, Barron K E and Elliot A J 1998 Educational psychologist 33(1) p 1

[17] Harris D 1931 No. 131

[18] Harris D 1940 1930 \pm 1937 Psychological Bulletin 37 p 125

[19] Haveman R and Wolfe B 1995 Journal of Economic Literature 23 p 1829

[20] Hurtado S, Han J C, Sáenz V B, Espinosa L L, Cabrera N L and Cerna O S 2007 Research in Higher Education 48(7) p 841

[21] Intan R 2016 Jurnal FISIP: Administrasi \& Kebijakan Publik $\mathbf{5}(2)$

[22] Jansen M, Lüdtke O and Schroeders U 2016 Contemporary Educational Psychology 46 p 116

[23] McGill R J and Dombrowski S C 2019 Applied Measurement in Education 32(3) p 216

[24] McGrew K S 2009 CHC theory and the human cognitive abilities project: Standing on the shoulders of the giants of psychometric intelligence research

[25] Neisser U, Boodoo G, Bouchard T J, Boykin A W, Brody N, Ceci S J and Urbina S 1996 American Psychologist 51(2) p 77

[26] Reed S L 2014 Some Correlation Between Mental Ability, and Age and Grades for College Freshmen. (Proceedings of the Oklahoma Academy of Science: Vol. 4 p 143).

[27] Roth W M and Hsu P L 2008 Educational psychology: Cognition and learning, individual differences and motivation (New York: McGraw Hill)

[28] Ryan R M and Deci E L 2000 Contemporary educational psychology 25(1) p 54

[29] Sternberg R J 1977 Psychological review 84(4) p 353

[30] Torenbeek M, Jansen E and Hofman A 2010 Studies in Higher Education 35(6) p 659

[31] Voyer D, and Voyer S D 2014 Psychological Bulletin 140(4) p 1174

[32] Yara P O and Otieno K O 2010 Asian Social Science 6(12) p 126 